\title{
Comparative Effects of Ballooning Intracervical Catheter and Prostaglandin Pessary on Cervical Ripening
}

\author{
Raheela Baloch ${ }^{1}$, Qamarunissa Muhabat' ${ }^{1}$, Fakhrunissa Waheed ${ }^{2}$, Waqarunissa Ahmed ${ }^{3}$ \\ ${ }^{1}$ Department of Obstetrics \& Gynecology, Aga Khan Maternity \& Child Care Hospital, Hyderabad Sindh, \\ Pakistan \\ ${ }^{2}$ Department of Obstetrics \& Gynecology, Indus Tando M. Khan, Hyderabad Sindh, Pakistan \\ ${ }^{3}$ Department of Obstetrics \& Gynecology, Shaikh Zayed Hospital, Larkana Sindh, Pakistan \\ Email: qamarunissanoonari@yahoo.com
}

Received 7 April 2016; accepted 31 July 2016; published 3 August 2016

Copyright (C) 2016 by authors and Scientific Research Publishing Inc.

This work is licensed under the Creative Commons Attribution International License (CC BY).

http://creativecommons.org/licenses/by/4.0/

c) (i) Open Access

\begin{abstract}
Labor is induced to stimulate the uterine contraction in effort to have vaginal birth. Induction may be advocated to reduce fetal or neonatal morbidity and mortality. Indication of labor needs to be considered when risk and benefits analysis indicates that delivering the baby is safe option for mother or both rather than continuing the pregnancy and when there are no clear indications for caesarean section and no contraindication for vaginal delivery.
\end{abstract}

\section{Keywords}

Induction, Foley's Cather, Prostaglandin

\section{Introduction}

Induction of labor is one of the most common procedures in obstetrics [1]. Labor induction is the artificial initiation of labor prior to its spontaneous onset and purpose to accomplishing delivery of feto-placenta [2]. Labor induction is defined as the stimulation of regular uterine contractions before spontaneous onset of labor, using mechanical or pharmacologic methods in order to generate progressive cervical dilation and subsequent delivery [3].

Worldwide, $20 \%$ - 30\% of deliveries are induced [4]. Unpublished data from WHO Global survey on maternal and perinatal health, which included 373 health-care facilities in 24 countries and nearly 300,000 deliveries, showed that $9.6 \%$ of the deliveries involved labor induction. Over all, the survey found that facilities in African countries tended to have lower rate of induction of labor (lowest: 1.4\% in Niger) compared with Asian and Latin 
American countries (Highest: 35.5\% in Srilanka) [5] [6].

Cervix is considered unfavorable if the derived score is less than 6 and cervical ripening is indicated prior to artificial rupture of membranes and oxytocin infusion to reduce the incidence of failed induction and caesarean delivery [7]. Induction should be considered when it is felt that the benefits of vaginal delivery out weight the potential maternal and fetal risks of induction. These issues should be discussed with the woman prior to initiation of induction.

One of the most common indications for induction is post term pregnancy with the gestational age of at least 41 completed weeks. Induction for this indication has been shown to reduce the likelihood of perinatal death [8] [9]. Other indications for induction include premature rupture of membranes [10] [11], potential fetal compromise (significant fetal growth restriction, non-reassuring fetal surveillance), maternal medical conditions, (TypeI diabetes, renal disease, significant pulmonary disease, hypertension—gestational or chronic), antiphospholipid syndrome, suspected or proven chronioamnionitis, abruption and fetal death. This list is not meant to be all inclusive.

Induction is sometimes performed for "social" or "geographic" reasons, without a medical or obstetric indication [12] [13]. There have been few well designed studies evaluating induction for this indication, with no randomized clinical trial since 1983 [14] [15], but the sample size did not provide adequate power to make these conclusions. A retrospective study [16] concluded that elective induction should be discouraged in then nulliparous women since the rate of cesarean delivery is increased with elective induction. A meta-analysis of early trials concluded that there is no benefit to elective induction and there is no place for it in term pregnancy [14]. The American College of Obstetricians and Gynecologists suggests that labor may be induced for logistic reasons, including risk of rapid labor, distance from hospital and psychosocial reasons [17].

Potential risks of induction include increased rate of operative vaginal delivery [14], caesarean birth [18], excessive uterine activity [19], abnormal fetal heart rate patterns, uterine rupture [20], and maternal water intoxication [21], delivery of preterm infant due to incorrect estimation of dates and possibly cord prolapse with artificial rupture of membranes [22].

The contraindications to induction of labor include contraindications to labor or vaginal delivery. Examples of this include previous myomectomy entering the uterine cavity, previous uterine rupture, fetal transverse lie, placenta previa, vasa previa, invasive cervical cancer, active genital herpes, and previous classical or inverted $\mathrm{T}$ uterine incision (except in unusual circumstances such as extreme prematurity) [23] [24].

Numerous techniques have been used to ripen the unfavorable cervix to achieve the changes necessary for labor [25]. Presently pharmacological and mechanical agents are used to modify the cervical status 2. Prostaglandins are the most commonly used pharmacological agents for ripening of cervix and prostaglandin E2 (PGE2) is the agent of choice for this purpose [26], but are expensive [27].

A variety of more economical mechanical methods are also used for cervical ripening like intracervical Foley catheter with or without extra amniotic saline infusion, bogies and hygroscopic laminaria tents. The use of Foley's catheter to effect cervical ripening was first described by Embrey and Mollison in 1967 [28]. There is clinical evidence which shows that the appropriate utilization of mechanical methods for pre-induction cervical ripening is safe, not expensive and with a similar success rate to that of intravaginal PGE2. The most commonly used mechanical method is the intracervical Foley's catheter [29].

Our study aimed to compare the safety and efficacy of prostaglandin E2 vaginal pessary and the cheaper intracervical Foley's catheter in women with unfavorable cervices (modified Bishop Score $\leq 4$ ).

\section{Data Collection Procedure}

During the study period, 100 patient were selected for cervical ripening and out of 100 fifty (50) patients had Intracervical Foley's catheter insertion, No-16-F catheter with 50CC saline in the blub (Group-I) and 50 had 3 mg of dinoprostone OR Prostaglandin E2 (PGE2) pessary (Group-II). Pre-induction cervical scoring was noted. After 6 hours change in bishop's score was noted in both groups. The cervical dilatation and improvement in bishop's cervical score and outcome of induction of labor were compared in both the group.

The protocol followed was as follows:

1) Time for score greater than 6 was noted and if the score still was less than 6 , then in cases of PGE2 pessary, reinstallation done after a period of 4 hours.

2) If score was more than 6 then all patients (of both groups) were subjected to artificial surgical anatomy of 
the membranes, followed by titrated oxytocin drip at rate of $1 \mathrm{mu} / \mathrm{min}$ and then increased by algebraic progression.

3) The course of labor was charted on a partograph in every case.

Indications for cervical ripening and induction of labor were:

Post term pregnancy.

Pregnancy induced hypertension/Toxaemia of pregnancy.

- Oligohydramnios.

- Intrauterine growth retardation.

- Suspected fetal jeopardy.

- Suspected placental insufficiency.

- Bad obstetrical history.

- Diabetes mellitus.

In cases of systemic illnesses like bronchial asthma, Foley's catheter was used as PGE2 was contraindicated. Prophylactic antibiotic was given to every patient.

Out of the total 100 patients studied, 50 had Foley's insertion, No-16-F catheter with 50 cc saline in the bulb (Group-I) and 50 had PGE2 pessary insertion (Group-II). These patients were admitted for induction of labor due to various indications described above. Under aseptic conditions patients kept in the lithotomy position, cervix was assessed on the Bishop's scoring scale. In Group I, cervical os was exposed with a bivalve speculum and Foley's catheter No-16 was inserted into the extra amniotic space and bulb was inflated with 50ml of normal saline, the distended bulb was hitched on the internal os and catheter was strapped to the abdomen for 6 hours. Prophylactic antibiotic was given.

After 6 hours, catheters were either removed by deflation of bulb, or were expelled out spontaneously. Bishop's cervical scoring was again repeated and if score was more than 6 , artificial rupturing of membranes was done for color of liquor, followed by induction of labor and augmentation with oxytocin at $1 \mathrm{mu} / \mathrm{min}$ with titration if Liquor was clear. In Group-II 3 mg dinoprostonePGE2 pessary was inserted intracervical by the withdrawal technique aseptically, patient lied recumbent for 30 minutes, repeat per vaginal examination was done later after 6 hours, improvement in Bishop's score more than 6 was noted. Fetal heart rate and uterine activity was monitor strictly and half hourly intrapartum monitoring of fetal heart rate on CTG machine and progress of labour on partograph recorded in all cases.

\section{Results}

During the study duration from 14 Feb 2011 to 13 Feb 2012 of the 100 women recruited in the study, study carried out at Gynecological ward of Liaquat University of Medical and Health Sciences Hospital Hyderabad.

Analysis of booking status listed in Table 1 revealed that $76.0 \%(\mathrm{n}=76)$ were un-booked having no antenatal care and $24.0 \%(n=24)$ were booked had statistically significant difference $\mathrm{P}=0.001$.

50 women had intracervical Foley catheter (Group I) and 50 had PGE2 pessary (Group II). There were no protocol violation, relation to the parity listed in Table 2 showed maximum number of patients $(n=52) 52.0 \%$ Primigravida and $(n=48) 48.0 \%$ multigravidas were included, had no significant difference $\mathrm{P}=0.143$.

Age distribution is listed in Table 3 maximum patients $(n=51) 51.0 \%$ at age between 26 - 35 years, 29 (29.0\%) were between 20 - 25 years, $16(16.0 \%)$ were $>35$ years and 04 (4.0\%) patients were belong to less than 20 years. Two groups had significant difference in maternal age $\mathrm{P}=0.002$.

Regarding the gestational age $69(69.0 \%)$ patients in our study presented between 37 - 39 weeks of gestation. However, 31 (31.0\%) patients were at $40->40$ weeks of gestation had a significant difference value 0.0014 (Table 4).

\begin{tabular}{cccc} 
Table 1. Booking status. & & & \\
\hline Distribution of cases & Number & Percentage & P-value \\
\hline Un-booked & 76 & $76.0 \%$ & 0.003 \\
Booked & 24 & $24.0 \%$ & \\
Total & 100 & 100 & \\
\hline
\end{tabular}


Table 2. Parity of patients.

\begin{tabular}{ccccc}
\hline Parity & Total No. & Foley's Catheter & PGE2 & P-value \\
\hline Primigravida & 52 & 26 & 26 & \\
Multigravidas & 48 & 24 & 24 & 0.143 \\
Total & 100 & 50 & 50 & \\
\hline
\end{tabular}

Table 3. Age distribution.

\begin{tabular}{cccc}
\hline Age (years) & No. of cases $(100)$ & Percentage & P-value \\
\hline$<20$ & 04 & $4.0 \%$ & \\
$20-25$ & 29 & $29.0 \%$ & 0.143 \\
$26-35$ & 51 & $51.0 \%$ & \\
$>35$ & 16 & $16.0 \%$ & \\
\hline
\end{tabular}

Table 4. Duration of gestation.

\begin{tabular}{cccc}
\hline Gestational age $(\mathrm{W})$ & Number & Percentage & P-value \\
\hline 37 - 39 weeks & 69 & $69.01 \%$ & \\
40 - > 40 weeks & 31 & $31.0 \%$ & 0.0014 \\
Total & 100 & & \\
\hline
\end{tabular}

Indication for cervical ripening and induction of labor is listed on Table 5 commonest indication was pregnancy induced hypertension followed by prolonged pregnancy in both groups, however Foley's catheter use in other indication (IUGR) etc.

Table 6 shows the Bishop score between Foley's catheter and Prostaglandin group. 9 (18\%) had Bishop Score 2 - 3 in Foleys catheter and 10 (20\%) patients had Bishop Score 2 - 3 in Prostaglandin group. Similarly, 41 (82\%) patients had Bishop Score 4 - 5 in Foleys catheter and 40 (80\%) had Bishop Score 4 - 5 in Prostaglandin group.

Table 7 shows induction-delivery interval was significantly shorter in Prostaglandin group than that in catheter group (11.58 hours vs. 19.45 hours; $\mathrm{P} \leq 0.002)$. Also greater number of women $(44 / 50)$ delivered within 24 hours of start of induction in Prostaglandin group than those in Catheter group (36/50) $\mathrm{P}=0.045$.

The mode of delivery did not reveal any significant difference in two groups listed in Table 8 .

Table 9 shows two babies had an APGAR score 4/10 at end of 1 min and 7/10 at end of 5 min in Prostaglandin group whereas all babies in Foley's catheter group had an APGAR score of 9/10 had no significant difference $\mathrm{P}=0.148$.

The indications for caesarean section are shown in Table 10. There were 04 (8\%) cases of failed induction in Foley's catheter group vs. 2 (4\%) in Prostaglandin group. However 4 (8\%) cases of fetal distress, 4 (8\%) cases of meconium stained liquor in the Prostaglandin group. There was no increased incidence of neonatal sepsis or chorioamniotis or puerperal sepsis in any of our patients. There was no accidental rupture of membranes while introducing Foley's catheter. No perinatal morbidity or mortality or any severe maternal complications were noted while mild side effects in either group were noted (Table 11).

\section{Discussion}

The need to ripe the cervix prior to induction of labor has become a reality in our lives as obstetricians. Analysis of the United States birth Statistics (National Center for Health Statistics) shows that approximately 10 percent of all Inductions require cervical ripening [30].

A randomized trial of use of prostaglandins and extra-amniotic saline infusion for cervical ripening and labor induction by Shyla et al. showed that both methods of labor induction to be equally effective [31]. 
Table 5. Indication for cervical ripening and induction of labor.

\begin{tabular}{ccc}
\hline Indication & Foley’s Catheter & Prostaglandin \\
\hline PIH/HT in pregnancy & $24(48 \%)$ & $30(60 \%)$ \\
Postdates & $12(24 \%)$ & $20(40 \%)$ \\
Other (IUGR) etc. & $14(28 \%)$ & 00 \\
\hline
\end{tabular}

Table 6. Bishops scoring scale and change in bishop score.

\begin{tabular}{ccc}
\hline Bishop's score & $\begin{array}{c}\text { Foley catheter } \\
(\mathrm{n}=50) \mathrm{n} \%\end{array}$ & $\begin{array}{c}\text { Prostaglandin } \\
(\mathrm{n}=50) \mathrm{n} \%\end{array}$ \\
\hline $2-3$ & $9(18 \%)$ & $10(20 \%)$ \\
$4-5$ & $41(82 \%)$ & $40(80 \%)$ \\
\hline
\end{tabular}

Table 7. Outcome of labor induction.

\begin{tabular}{cccc}
\hline & Foleys catheter & Prostaglandin & P-value \\
\hline Induction-delivery & 19.45 & 11.58 & $<0.002$ \\
interval (hours) & $(5.48-40.25)^{\mathrm{a}}$ & $(6-55.13)^{\mathrm{a}}$ & \\
Number of delivered within & $36 / 50$ & $44 / 50$ & 0.045 \\
24 hour & $(72)^{\mathrm{b}}$ & $(88)^{\mathrm{a}}$ & \\
\hline
\end{tabular}

Table 8. Mode of delivery.

\begin{tabular}{ccc}
\hline Mode of delivery & Foley’s Catheter & PGE2 P-value \\
\hline Normal vaginal delivery & $40(80 \%)$ & $37(74 \%) 1.06$ \\
Forceps delivery & Nil & $02(4 \%) 0.06$ \\
Vacuum delivery & $6(12 \%)$ & $01(2 \%) 1.0$ \\
LSCS & $4(8 \%)$ & $10(20 \%) 1.03$ \\
\hline
\end{tabular}

Table 9. Apgar score.

\begin{tabular}{ccccc}
\hline & Score & Foley's Catheter & PGE2 & P-value \\
\hline APGAR at 1 min & $4-6$ & Nil & 02 & \\
& $7-8$ & Nil & Nil & \\
& $9-10$ & 50 & 48 & \\
APGAR at 5 min & $4-6$ & Nil & Nil & 0.148 \\
& $7-8$ & Nil & 02 & \\
\hline
\end{tabular}

Table 10. Indication of LSCS.

\begin{tabular}{cccc}
\hline Meconium stained liquor & Foley’s Catheter & PGE2 & $04(8 \%)$ \\
\hline $\begin{array}{c}\text { Fetal distress } \\
\text { (non-reactive CTG) }\end{array}$ & Nil & $02(4 \%)$ & 0.07 \\
Failed induction & $04(8 \%)$ & Nil & \\
Uterine hyper stimulation & Nil & & \\
\hline
\end{tabular}


Table 11. Side effects.

\begin{tabular}{ccc}
\hline Side effects & Foley's Catheter & PGE $_{2}$ \\
\hline Nausea & Nil & 24 \\
Vomiting & Nil & 10 \\
Diarrhea & Nil & 02 \\
Fever & Nil & 05 \\
Accidental rupture of membrane & Nil & Nil \\
Chorioamniotis & Nil & Nil \\
Infection & 03 & Nil \\
Uterine hyper stimulation & Nil & Nil \\
\hline
\end{tabular}

Several studies have been shown superiority of the Foley's balloon catheter over the other techniques, resulting in improved cervical Bishops score increase rate of labor induction and higher number of vaginal deliveries [32] [33].

In our study most of patients $(\mathrm{n}=76,76.0 \%)$ were unbooked having no antenatal care that indicates the lack of antenatal care is a major contributing factor for maternal and fetal morbidity and mortality.

A study done in Karachi revealed that women receiving antenatal care were more knowledgeable about the importance of nutrition and health awareness [34].

In our study $(n=26,52 \%)$ women were primary gravidas and $(n=24,48 \%)$ were multigravidas in Foley Catheter group, while it was not matched with the study done in Dhaka. Similarly $(n=26,52 \%)$ women were primary gravidas and $(n=24,48 \%)$ were multigravidas in prostaglandin group, while it was contradict with the study done in Dhaka. In both groups there was no significant difference regarding gravidity $(\mathrm{P}=1.00)$.

Maximum patients were seen in age group of 26 - 35 years (51\%) while $16 \%$ patients were above 35 years of age and $04 \%$ patients were below 20 years of age.

Minimum and maximum gestational age were $37 \& 42$ weeks respectively while minimum gestational age was 28 weeks in the study of F. Dewan [35], while maximum gestational age was 42 weeks in the study of F. Dewan that was similar with our study [35].

The common indications for induction of labour was Hypertensive disorders of pregnancy it was given 24 (48\%) in Foleys catheter group, while 22 (44\%) in Prostaglandin group, while it was lower in the study done in Dhaka while it was matched with the study done in Punjab [36].

Second most common indication was postdates done in 2 (24\%), 12 (24\%) respectively it was closer with the other studies [35] [36]. In our study 14 patients (28\%) had given induction due to IUGR in Foley catheter group patients and 08 patients (16\%) had given Prostaglandin pessary while it was lower in the study done in Punjab [36].

In our study 9 patients (18\%) had Bishop Score 2 - 3 in Foley catheter group and 10 patients (20\%) had Bishop Score 2 - 3 in prostaglandin group. Similarly 41 (82\%) patients had Bishop Score 4 - 5 in Foley catheter and $40(80 \%)$ in a prostaglandin group. These results correlate with the study done in Dhaka [35].

Induction delivery interval was significantly shorter in prostaglandin group than that of Foley catheter group. (11.58 hours versus 19.45 hours, $\mathrm{P} \leq 0.002$ ). The results were similar with the study done in Punjab [36] while contradict with the studies done by F. Dewan [35] and E. L. Torkey et al. [37].

Greater number of new women 44/50 (88\%) delivered within 24 hours of start of induction in prostaglandin group then those in a catheter group $36 / 50(\mathrm{P}=0.045)$. The results were similar in different studies [35] [36].

The time from start of induction to the birth was substiantionally longer with the Foley catheter group; it was similar with the study of Martafozwik [38].

Number of caesarean sections was $10(8 \%)$ in prostaglandin group, where as it was $4 \%$ in Foley catheter group. Though there was higher caesarean section in prostaglandin group but statistically there was significant difference between these two groups, while the caesarean section was 9 (20\%) in prostaglandin group and 8\% (17.8\%) in Foley catheter group in the study done in Bangladesh [39].

The caesarean section was apparently higher in prostaglandin group because of Meconium stained liquor, fet- 
al distress and failed induction. It was $4 \%, 4 \%, 2 \%$ respectively. These patients were immediately treated with oxygen therapy, Left lateral positioning, followed by emergency caesarean section. Our findings along with results of other randomized controlled trials [40]-[42]. Shows that, Foley's catheter and prostaglandin pessary give similar vaginal delivery rate although we hypothesized that Foley's catheter reduce caesarean delivery.

Caesarean section deliveries done because of failed induction were seen more often whereas caesarean section deliveries for fetal distress were not seen with the use of prostaglandin same was reported by the study done in Netherland [38].

Two of ten newborns had poor Apgar score at one minute but they improved subs intentionally and five minute APGAR score becomes 10 after neonatal resuscitation.

The main argument against the use of this method could be the risk of introduction of infection because many potential pathogens inhabit vagina and end cervix. But the improvement was not quantitatively assessed. These risks can be eliminated by aseptic precaution, use of aseptic techniques during the insertion of the catheters and the use of sterile water for inflating the balloon. In the present series, it was not possible to ensure that there was no obvious vaginal infection in all of these patients as there were limited facilities for culture and sensitivity tests of high vaginal and endocervical swabs. We have taken high vaginal swabs (HVS) in 10 patients of the Foley catheter group to detect infection. Among them in three (20\%) cases there was mild growth of organism, which responded promptly to antibiotics. Garry et al. [43] states that the presence of catheter can be a constant risk of infection. But Sandhu et al. [44] in their study reported that the rate of infection with Foley's catheter method is not significant and is comparable to the incidence of hospital acquired infection as stated by different authors using different procedures.

\section{Conclusion}

Though prostaglandins are currently most commonly accepted and widely used agents for the ripening of unfavorable cervix and for induction of labour in the developed countries, but they are associated with some problems, such as absorption, unpredictable patient response, vomiting, diarrhea, tachycardia, fever, bronchospasm, and sometimes unavoidable irreversible hypertonic uterine contraction. An alternative approach for cervical ripening has been sought. This alternative approach should be safe, easy available, preserved at normal temperature, as effective as prostaglandins, cost-effective, less side effects and acceptable to the patients as well as to the physicians. Foley's catheter for cervical ripening has been found as an alternative method to prostaglandins, as it has almost all the expected criteria; its inducibility rate is high and the success rate is $80 \%$ in our study. The potential advantages of Foley's catheter over prostaglandin $E_{2}$ are low cost and reversibility.

\section{References}

[1] Lisa, E. and Moore, M.D. Division of Maternal-Fetal Medicine. Department of obstetrics and Gynaecology, MSC 105580, University of New Mexico, Albuquerque.

[2] Mackenzie, I.Z. (1994) Labour Induction including Pregnancy Termination for Fetal Anomaly. In: James, D.E., Steer, P.J., Weiner, C.P. and Gonik, B., Eds., High Risk Pregnancy, Management Options, WB Sounders, London, 104-159.

[3] Wolf, J.P., Sinosich, M., Anderson, T.L., Ulman, A., Bauliac, E.E. and Hodgen, G.D. (1989) Progestreneautagonist (RU 486) for Cervical Dilation, Labor Induction, and Delivery in Monkeys: Effectiveness in Combination with Oxytocin. American Journal of Obstetrics \& Gynecology, 160, 45-47. http://dx.doi.org/10.1016/0002-9378(89)90084-7

[4] Boulvain, M., Stan, C., Irion, C. and Irion, O. (2008) Membrane Sweeping for Induction of Labour. Cochrane Review. The Cochrane Library.

[5] Delee, J.B. (1992) Preparatory Obstetric Operations. In: The Principles and Practice of Obstetrics, 5th Edition, WB Sounders, Philadelphis, 966.

[6] Bishop, E.H. (1964) Pelvic Scoring for Elective Induction Obstetric. Gynaecology, 24, 266-268.

[7] Hannah, M.E., Ohlsson, A., Farine, D., Hewson, S.A., Hodnett, E.D., Myhr, T.L., et al. (1996) Induction of Labour Compared with Expectant Management for Prelabour Rupture of the Membranes at Term. New England Journal of Medicine, 334, 1005-1010. http://dx.doi.org/10.1056/NEJM199604183341601

[8] Hannah, M.E., Hannah, W.J., Hellmann, J., Hewson, S., Milner, R., Willana, A., and the Canadian Multicenter Post Term Pregnancy Trial Group (1992) Induction of Labour as Compared with Serial Antenatal Monitoring in Post Term Pregnancy. A Randomized Controlled Trial. New England Journal of Medicine, 326, 1587-1592.

http://dx.doi.org/10.1056/NEJM199206113262402 
[9] Crowley, P. (2000) Interventions for Preventing or Improving the Outcome of Delivery at or beyond Term (Cochrane Review). In: The Cochrane Library, No. 3, Update Software, Oxford.

[10] Macdonald, D. (1970) Surgical Induction of Labour. American Journal of Obstetrics \& Gynecology, 107, 98.

[11] Jackson, M. and Regan, C. (1997) Elective Induction of Labour. Clinical Obstetrics and Gynecology, 40, 496-509. http://dx.doi.org/10.1097/00003081-199709000-00007

[12] Tan, B.P. and Hannah, M.E. (2000) Prostaglandins for Prelabour Rupture of Membranes at or near Term (Cochrane Review). In: The Cochrane Library, No. 3, Update Software, Oxford.

[13] Zlatnik, F.J. (1999) Elective Induction of Labour. Clinical Obstetrics and Gynecology, 42, 757. http://dx.doi.org/10.1097/00003081-199912000-00005

[14] Crowley, P. (1995) Elective Induction of Labour at or beyond Term. The Cochrane Pregnancy and Childbirth Database.

[15] Macer, J.A., Macer, C.L. and Chan, L.S. (1992) Elective Induction versus Spontaneous Labor: A Retrospective Study of Complications and Outcome. American Journal of Obstetrics \& Gynecology, 166, 1690-1697. http://dx.doi.org/10.1016/0002-9378(92)91558-R

[16] ACOG Practice Bulletin (1999) Induction of Labour No. 10.

[17] Seyb, S.T., Berka, R.J., Socol, M.L. and Dooley, S.L. (1999) Risk of Cesarean Delivery with Elective Induction of Labour at Term in Nulliparous Women. Obstetrics \& Gynecology, 94, 600-607.

[18] Kelly, A.J., Kavanagh, J. and Thomas, J. (2001) Vaginal Prostaglandin (PGE2 and PGF2) for Induction of Labour at Terms (Cochrane Review). In: The Cochrane Library, Issue 2, Update Software, Oxford.

[19] Flannelly, G.M., Turner, M.J., Rassmussen, M.J. and Stroge, J.M. (1993) Rupture of the Uterus in Dublin an Update. Obstetrics and Gynaecology, 13, 440-443. http://dx.doi.org/10.3109/01443619309151734

[20] Whalley, P.J. and Pritchard, J.A. (1963) Oxytocin and Water Intoxication. JAMA, 186, 601-603. http://dx.doi.org/10.1001/jama.1963.63710060047021d

[21] Trofatter, K.F. (1992) Cervical Ripening. Clinical Obstetrics and Gynecology, 35, 476-485. http://dx.doi.org/10.1097/00003081-199209000-00007

[22] Brien, W.F. (1995) Cervical Ripening and Labour Induction Progress and Challenges. Clinical Obstetrics and Gynecology, 38, 221-223. http://dx.doi.org/10.1097/00003081-199506000-00004

[23] Niromevesh, S., Mosavi-Jarrali, A. and Sankhaniani, F. (2003) Intra Cervical Foley Catheter Balloon vs Prostaglandin in Pre Induction Cervical Ripening. International Journal of Gynecology \& Obstetrics, 81, 23-27. http://dx.doi.org/10.1016/S0020-7292(02)00392-2

[24] James, C., Peedicayil, A. and Seshadril, L. (1994) Use of Foley Catheter as a Cervical Ripening Agent Prior to Induction of Labour. International Journal of Gynecology \& Obstetrics, 47, 229-232. http://dx.doi.org/10.1016/0020-7292(94)90566-5

[25] Asaf, K.H., Yusuf, A.W., Rauf, S. and Raza, S. (1998) Induction with Prostaglandin E2 Vaginal Pessaries: A Success. Pakistan Journal of Obstetrics \& Gynaecology, 11, 45-49.

[26] Mazhar, S.B. and Alam, K. (2001) Induced Labour: Indication and Outcome, PIMS Experience. Journal of Surgery, 23-24, 31-33.

[27] Embrey, M.P. and Mollison, B.G. (1967) The Unfavourable Cervix and Induction of Labour Using a Cervical Balloon. BJOG, 74, 44-48. http://dx.doi.org/10.1111/j.1471-0528.1967.tb03931.x

[28] Gaucherand, P., Delignette, M., Gelas, M. and Rudigoz, R.C. (1991) Declenchement de travail de accouchement par les prostaglandins. Revue Française de Gynécologie et d'Obstétrique, 86, 647-652.

[29] Ghezzi, F., Massimo, F., Raio, L., et al. (2001) Extra Amniotic Foley Catheter and PGE2 Gel for Cervical Ripening at Term Gestation. European Journal of Obstetrics \& Gynecology and Reproductive Biology, 97, 183-187. http://dx.doi.org/10.1016/S0301-2115(00)00544-3

[30] Rix, P., Ladehoff, P., Moller, A.M., Tilma, K.A. and Zdravkovic, M. (1996) Cervical Ripening and Induction of Delivery by Local Administration of Prostaglandin E2 Gel or Vaginal Tablets Is Equally Effective. Acta Obstetricia et Gynecologica Scandinavica, 75, 45-47http://dx.doi.org/10.3109/00016349609033282

[31] Vengalil, S.R., Guinn, D.A., Olabi, N.F., Burd, L.I. and Owen, J. (1998) A Randomized Trial of Misoprostol and Extra-Amniotic Saline Infusion for Cervical Ripening and Labor Induction. Obstetrics and Gynaecology, 91, 774-779.

[32] Agudelo, A.C. and Belizan, J.M. (2000) Risk Factors for Pre-Eclampsia in a Large Cohort of Latin American and Caribbean Women. BJOG, 107, 75-83. http://dx.doi.org/10.1111/j.1471-0528.2000.tb11582.x

[33] Atad, J., Hallak, M., Austender, R., Porat-Packer, T., Zarfali, D. and Abramovici, H. (1996) A Randomised Comparison of Prostaglandin E2, Oxytocin and the Double-Ballon Device in Inducing Labor. Obstetrics and Gynaecology, 87, 
223-227. http://dx.doi.org/10.1016/0029-7844(95)00389-4

[34] Rouben, D. and Arias, F. (1993) A Randomized Trial of Extra-Amniotic Saline Infusion plus Intracervical Foley Catheter Balloon versus Prostaglandin E2 Vaginal Gel for Ripening the Cervix and Inducing Labourin Patients with Unfavorable Cervix. Obstetrics and Gynaecology, 92, 290-294.

[35] Dewan, F., Begum, R. and Chowdhury, S.B. (1995) Comprative Study of Induction of Labour by Foley Catheter with That of Sweeping of the Membrane in Prolonged Pregnancy. Sir Salimullah Medical College, 3, 22-27.

[36] Manabe, Y., Manabe, A. and Takahashi, A. (1982) Prostaglandin Levels in Amniotic Fluid during Balloon-Induced Cervical Softening and Labor at Term. Prostaglandins, 23, 247-256. http://dx.doi.org/10.1016/0090-6980(82)90052-1

[37] Sandhu, S.K., Arora, S. and A.S. (1984) Journal of Obstetrics and Gynaecology of India, 34, 226.

[38] American College of Obstetrician and Gynaecologists Committee Opinion (1998) Monitoring during Induction of Labor with Dinoprostone. Committee Opinion 209,Washington DC, ACOG, 11.

[39] Pennell, C.E., Henderson, J.J., O’Neill, M.J., McCleery, S., Doherty, D.A. and Dickinson, J.E. (2009) Induction of Labor in Nulliparous Women with an Unfavorable Cervix: A Randomized Controlled Trial Comaring Double and Single Balloon Catheters and PGE2 Gel. BJOG, 116, 1443-1452. http://dx.doi.org/10.1111/j.1471-0528.2009.02279.x

[40] Prager, M., Eneroth-Grimfors, E., Edlund, M. and Marions, L. (2008) A Randomized Controlled Trial of Intravaginal Dinoprostone, Intravaginal Misoprostol and Transcervical Balloon Catheter for Labour Induction. BJOG, 115, 14431450. http://dx.doi.org/10.1111/j.1471-0528.2008.01843.x

[41] Ezimokhai, M. and Nwabinelli, J.N. (1980) The Use of Foley’s Catheter in Ripening the Unfavourable Cervix Prior to Induction of Labour. BJOG, 87, 281-286. http://dx.doi.org/10.1111/j.1471-0528.1980.tb04540.x

[42] Smith, M.A., Swan, L., Caruthers, B.S. and Heaton, C. (1990) Outpatient Use of Prostaglandin Gel for Ripening of the Cervix and Induction of Labor. The Journal of Family Practice, 30, 656-664.

[43] Garrey, M.M., Goran, A.D.I. and Hodge, C. (1990) In: Obstetrics Illustrated, 3rd Edition, Churchill Livingstone, 448.

[44] Barkai, G., Cohen, S.B. and Kees, L. (1997) Induction of Labor with Use of a Foley Catheter and Extraamniotic Corticosteroids. American Journal of Obstetrics and Gynecology, 177, 1145-1148.

\section{Submit or recommend next manuscript to SCIRP and we will provide best service for you:}

Accepting pre-submission inquiries through Email, Facebook, LinkedIn, Twitter, etc.

A wide selection of journals (inclusive of 9 subjects, more than 200 journals)

Providing 24-hour high-quality service

User-friendly online submission system

Fair and swift peer-review system

Efficient typesetting and proofreading procedure

Display of the result of downloads and visits, as well as the number of cited articles

Maximum dissemination of your research work

Submit your manuscript at: http://papersubmission.scirp.org/ 